\title{
Psychological and Pedagogical Direction of Music
}

\author{
Aftimichuk Olga* \\ Gymnastics, State University of Physical Education and Sports, Moldova, Europe
}

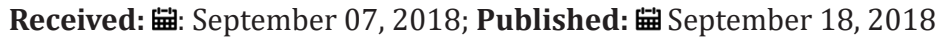

*Corresponding author: Aftimichuk Olga, Gymnastics, State University of Physical Education and Sports, Moldova, Europe

\begin{abstract}
The given research represents a theoretical study of the problem of the psychological and pedagogical influence of music on a person. The article reflects the retrospective of the birth of musical psychology, the educational and communicative side of music. Attempts have been made to study theoretically the psychophysical and psycho physiological properties of music, which allow one to reveal the effectiveness of its influence on the human nervous system. In addition, music unites the moral and aesthetic culture on the path to the formation of spirituality, which reflects its moral, ethical and aesthetic aspects. The author concludes that correctly selected music influences the purposeful activity of a person, since it promotes such a restructuring of the organism, which causes more efficient course of physiological processes. At the same time, its use in training specialists not only in pedagogical professions, but also in those professions where one has to work directly with the human resource in labour activity, will contribute to the formation of personal qualities necessary for the full and effective implementation of multilateral professional activities.
\end{abstract}

Keywords: Music; Psychology; Physiology; Pedagogy; Moral Ethical; Aesthetic Education

\section{Introduction}

\section{Prerequisites for the birth of musical psychology}

Along with general psychology, musical psychology dates back to the ancient times. Therefore, Pythagoras compared public activities, both with a musical style, and with an orchestra in which each person, like an instrument in an orchestra, has got his own role. They created the doctrine of eurhythmy, which was understood as a person's ability to find the right rhythm in all life manifestations. Pythagoras declared that through finding the right rhythm a person can enter the rhythm of the life of his city, and then connect to the rhythm of the world whole - the cosmos, based on the laws of universal harmony. Also, Pythagoras found that certain melodies and rhythms exert a corresponding influence on the mental state of people [1]. According to Plato, the strength and power of the state depends on what kind of music it sounds, in which modes and rhythms.

The ancient Greek philosopher believed that in a country is permissible only that music which helps to rise to human being [2]. According to Aristotle, music is a means of harmonizing the individual with society. He developed the doctrine of mimesis, which presupposed an idea of the inner world of human and ways of influencing him by means of art. Within the framework of the theory of mimesis, Aristotle developed the concept of catharsis, according to which, when contemplating theatrical performances, the soul of the viewer and listener is freed from painful affects. Aristotle believed that in the process of deep empathy a person is cleansed spiritually, and his personal/private life grows from one's identity to universality, implying social life under it [3].Aristotle has testified about the impact of music on the mental condition of the person, described in details the musical modes, some of which make a person compassionate and tender, others - contribute to the emergence of irritation or excitement.

The same conclusions applied to musical instruments. At the same time Aristotle pointed to the educational nature of music. He wrote: "Rhythm and melody contain in themselves the closest to the real reality of a display of anger and gentleness, courage and moderation and all the opposite properties, as well as other moral qualities. This is clear from experience: when we perceive our rhythm and melody with our ear, our mood changes $(6,1340$ and 19-23) [4]. The educational function of music was endowed even in ancient China, where it was considered a symbol of order and civilization. Music was the most important element of the education of young people and was one of the sciences that were compulsory for study. The Chinese philosopher Confucius (551-479 BC) himself played the ancient guqin (Ancient Chinese 7 -stringed plucked musical instrument) and proclaimed, that one who knows music deeply understands the rules of conduct and ritual. Therefore, people who have comprehended music and ritual can be considered to have achieved perfection in behaviour, which, according to Confucius, is the property not only of human being himself, but of the whole society [5]. 


\section{The Origin of Music Psychology}

However, scientific musical psychology originates in the work of the German naturalist. The doctrine of auditory sensations as the physiological basis of the music theory [6]. He developed a resonant theory of hearing, according to which auditory sensations arise in us through the resonance of internal organs of hearing in response to the external influences. The physiological basis of musical psychology can be found in the researches of physiological scientists IM Sechenov - in works relating to cerebral reflexes, and I.P. Pavlova - in the doctrine of higher nervous activity, the reflex character of the psyche, the study of the 2 nd signal system.

A great contribution to the development of science made German psychologists and musicologists [7-10], as well as the Swiss composer and teacher Émile Jaques-Dalcroze [11]. A significant contribution to the development of musical psychology was made by such Russian composers, musicologists, music psychologists and teachers as BV Asafiev [12,13] NA Garbuzov [14,15] LA Mazel and VA Zuckerman [16] VV Medushevsky [17] EV Nazaikinsky [18] BM Teplov [19] and others.

\section{Educational Direction of Music}

In the researches of VV Medushevsky [17] EV Naseikinsky [18] BM Teplov [19] AN Sohor [20] it was tried to consider musical perception as a process organically connected with the personality of a person in all the diversity of its relations with reality. Their work draws attention to the fact that a person's perception of the world around him proceeds from his own interests, moods, expectations, and holistic orientations of the subject. The research of VI Petrushin [21] confirmed earlier facts that the content of perceived musical images is influenced not so much by the musical abilities that the listener possesses at the time of meeting with music, but rather by the values and associated moods that form the core of the listener's personality. Psychological science proves that in any activity, including in the process of perception, a person always introduces his individual traits, his personal characteristics. AA Bodalev, for example, notes that "the study of the characteristics characterizing the formation of an impression of another person made it possible to establish how the cognizing subject can "invest" his states in another personality, attribute to it features that are in fact inherent in himself [22].

All this, in turn, allows us to declare that musical art by virtue of its natural polysemy provides opportunities for carrying out projective research in the study of the listener's personality. Although in the musical science the projective methods of investigating the personality have not been applied yet, the closest thing to the solution of this problem gave G.L. Golovinsky [23]. The nature of perception is influenced, as G.L. Golovinsky believes, by the general culture of the social environment, the circle of reading accepted in it, the selection of preferred types of art, the experience of their perception by the listener, his psycho physiological characteristics at the time of listening, and many other factors. In other words, the content of musical images reflects the characteristics of the value orientation of listeners. Thus, according to V.I. Petrushin [21], if one knows why a person is sad, angry or rejoiced, one can judge about his social maturity, which manifests, in particular, in the assimilation of socially significant norms and requirements.

To hear in the sounds of music the reflection of the subtlest spiritual movements and the expression of serious and profound experiences is not given to every person. In order to teach the listener to experience feelings and moods, expressed by the composer with the help of sounds specially organized, it means to develop in him a musical perception that presupposes a process of active cocreation and empathy with the image presented [24]. In this case, music represents the language of non-verbal communication. Like human speech, the mechanism of which is language [25], music has its own structure (motive, phrase, sentence, period), its means of expression (rhythm, tempo, dynamic shades, accents, intonation, harmony, order, melody, etc.). It, like the speech, is able to exist in the mind of a person without the direct presence of a language system. Moreover, for the formation of musical images in the minds of the listener language is not required, although the understanding of music is available to conscious comprehension and some verbal design. At the same time, music itself is the language of communication, the most faithful guide to the emotional world of a person. And where the word is already powerless, music comes into its own, which is consonant with the expression of the German poet and publicist Heinrich Heine [26]: "... where words end, music begins."

\section{The Communicative Side of Music}

However, the comprehension of the music language is impossible without reliance on the language of speech. This was pointed out by the outstanding teacher VA Sukhomlinsky: "The word can never fully explain the depth of the music, but without a word one can not approach this subtle sphere of feelings [27]. Expressiveness of the music language in many ways can be compared with the expressiveness of speech. On this basis, there is a hypothesis about the origin of music from speech intonations, which are always emotionally coloured [28]. And indeed, there is much in common between music and speech, because both musical sounds and speech are perceived by hearing. Speech intonation has the same expressive possibilities - timbre, height, voice power, tempo and rhythm of speech, accents, pauses, as musical intonation [29].

Academician BV Asafiev [12] scientifically substantiated the paradigm of musical art as an intonational art consisting in the embodiment of the emotionally-semantic content of music, similar to the embodiment of speech in the intonation of a person's inner state. By the means of speech intonation, a person expresses his feelings, moods, thoughts. For example, a person's agitated speech is characterized by an accelerated pace, continuity or, conversely, the presence of small pauses, an increase in the voice register, and the presence of accents. The same happens in music. The music that transmits confusion usually uses the same means: the music is performed at an accelerated or fast pace, the melody has a series of accents and the climax of the summit, suggesting an output to the upper register, etc. 


\section{Psychophysical and Psycho Physiological Properties of Music}

Here it should be noted that the origin of music and speech is due to the sound. "... At first there was the sound, wrote VP Asafiev [13] and only after listening to the nature of the sound, a man has made a word out of it ... ". In this aspect, scientists consider language as part of the natural environment encompassing human activity, since sound is a universal means of communication in the natural world. Since sound represent by itself a physical characteristic of wave origin, there it is necessary to indicate its rhythmic structure. Herewith it should be noted that a person possesses his own set of rhythm structures, called biorhythms [30]. Of particular interest are the biorhythms of the brain. According to the data of psychophysiology [31-33] the nature of the wave, its frequency, magnitude of amplitude can establish, albeit in general terms, the specific behaviour of a particular person. Individuals with high amplitude of alpha rhythm are characterized as calm, balanced, self-confident. Low amplitude of alpha rhythm observes opposite traits: tension, anxiety, inadequacy of behavior in an extraordinary situation.

The English psycho-physiologist Gray Walter points out the presence of a speed limit imposed by the frequency of alpha rhythm on the speed of our mental processes: "A faster rhythm, undoubtedly, has value within the life struggle. An effective difference between alpha-rhythms, let's say, with 8 and 13 oscillations per second is manifested in the possible quickness of stopping a car: at a speed of $80 \mathrm{~km} / \mathrm{h}$, the driver with a fast alpha rhythm wins $1.5 \mathrm{~m}$ of the braking distance. Therefore, pedestrians and cyclists with faster alpha rhythms are more likely to avoid a catastrophe [33]. Rhythmic pulsation with a speed of 8 sounds per second (alpha rhythm) can be traced in the finale of the Third Piano Concerto by Ludwig van Beethoven, in many military marches. The sound movement, corresponding to the rhythmic frequency of the beta rhythm, can be traced in many virtuosic plays - sketches by Frederic Chopin, Franz Liszt, Niccolo Paganini. In this perspective, the delta rhythm of the brain can be correlated with the rhythmic pulsation of three sounds per second, which can be heard in the Lunar Sonata of Ludwig van Beethoven, in many nocturnes by F. Chopin [21].

The given information suggests that when the musical rhythm is perceived, the brain's biorhythms involuntarily adjust to its frequency. And this is indicative when different emotional experiences arise. Thus, the strongest experiences can arise at the moment of coincidence of the dominant biorhythm with the frequency of musical rhythmic pulsation, which is the so-called resonance [31]. Since 1940, A.A. Ukhtomsky have pointed out that, for the most effective action on the nervous system, "it is required to know the range of the rhythms available to assimilation in it" and that "the key to domination is created through a tactfully selected and persistently sustained rhythm of influences [34]. Thus, correctly selected music influences the purposeful activity of a person, since it promotes such a rhythmic restructuring of the organism, which causes a more efficient course of physiological processes. According to these provisions in order to study the activity of the brain, physiologists use the method of Reaction of imposing rhythm.

This reaction will depend on the property of the human nervous system, which implies a force-weakness parameter. In this aspect, it was found that in individuals with a weak nervous system, which corresponds to a high sensitivity, a more pronounced reaction of the rearrangement of biorhythms to a relatively large frequency band is observed. For a person with a strong nervous system, which is less sensitive, the reaction of imposing the rhythm is less pronounced. Studies show that people with a weak nervous system, in comparison with a strong nervous system, are characterized by higher coefficients of imposing low frequencies of 4 and 6 times/s [31]. Speaking of musical perception, it can be assumed that, most likely, persons with a weak nervous system will be much thinner and deeper to feel and experience the content of musical works. The same, for those who are the owners of a strong type of higher nervous activity, is preferable the music written in a fast tempo (allegro), on dynamic forte shades and long-lasting sound.

Conversely, holders of a weak type will gravitate toward calm (adagio) and quiet (piano) music. The mentioned above leads us to the conclusion that music is capable of conveying the emotional state of a person, the wealth of his feelings that can be observed in the real life BM Teplov wrote: "In the most direct and immediate sense, the content of music is represented by feelings, emotions, moods [19]. Since music has the ability to transmit a change of moods, experiences, dynamics of emotional and psychological states, each music production, according to the psychologist VG Razhnikova, has a kind of sensual program [35].

\section{The Moral and Aesthetic Impact of Music}

But music not only affects the inner psychological state of a person. As it was noted even in the ancient times, to a certain extent, it is capable of forming its ideology and worldview. The ideological influence of music is manifested in the formation of a person's those or other ethical attitudes. Aristotle explained the phenomenon of the ethical influence of music by the fact that in its essential basis there are certain "embryos of moral states" which, according to his opinion, give the music the status of an obligatory pedagogical discipline: "A melody contains movements, these movements are active, and actions are signs of ethical properties ... music can have a certain effect on the ethical side of the soul; and once the music has such properties, then, obviously, it should be included among the subjects of youth education [3].

Moral and aesthetic culture is considered an important component of human spirituality. It is not by chance that the level of spirituality of a person is judged by the state of moral experience, the manifestation of aesthetic taste, and also by education that is oriented toward the development of cultural values. Among the many educational means an important place belongs to music. It awakens in a person the idea of the sublime, majestic, pure and beautiful in life. Music unites moral and aesthetic culture on the path of spirituality formation. Ancient aesthetics proclaimed that spirituality manifests itself as a process of harmonizing thought 
and feeling, and where harmony there is beauty and aesthetics [4]. Moral and aesthetic education contributes to the formation of humanism, which is the principle of worldview, which is based on:

a) conviction of the limitless possibilities of human being and his ability to self-improvement;

b) the requirement of freedom and protection of the dignity of the individual;

c) the idea of the human right to happiness and that the satisfaction of both spiritual and material needs and interests should be the ultimate goal of society [36].

And, since the very concept of humanity presupposes a real activity side, which characterizes the person's spiritual and moral qualities, his culture as a whole, then, humaneness, as a person's quality, is first of all understood as the activity side of a person's behavior reflecting his spiritual and moral values in the relation to other people and nature as a whole, manifested in charity, philanthropy, humanity, compassion and kindness [37]. From these points of view, the system of education of moral and aesthetic culture is possible by means of music. This, in turn, presupposes the choice of musical works, the content and forms of which should be aimed at the formation of a person's moral and aesthetic culture. This way, the exercise of spiritual and moral education is feasible, since music has a great power of emotional impact and is therefore an important means of forming ideological convictions, moral and aesthetic ideals.

It is possible to speak about the high culture of the listener of music not when he shows emotions on the music he likes, but when his experiences reveal a socially significant meaning, consisting of certain relations of the listener with other people and his connection with the whole society. In other words, the listener's emotions do not appear as a function of his personal spiritual life, but as a phenomenon that has objective meaning and significance, appearing as a transitional stage from psychology to ideology. It can be also affirmed that the listener's experiences have the same objective meaning and significance. And therefore, the more and more clearly they are expressed in him, the more he is at a higher stage of social and moral development. Such a common essence of musical perception and musical experience can be observed in the perception of the same music, when one person imagines pictures and images of the New Year carnival or circus performance, and the other sees images of joy on the occasion of achieving a socially significant goal. This demonstrates the whole subjectivity of the perception of the musical work and states that there is a great difference in the level of the scale of the person's personality.

\section{Conclusion}

The foregoing allows us to assert that properly selected musical works can be used in the educational process in the training of pedagogical personnel, since this will contribute to the formation of personal qualities necessary for the full and effective implementation of multilateral professional activities. In addition, the method of using music, in our opinion, takes place also in the training of specialists in those professions where in the work activity it is necessary to work directly with the human resource.

\section{References}

1. Kozlov VV (2009) Psychology of breathing, music, movement. Moscow: MAPS, Russia.

2. Malevansky GV (1983) The musical and astronomical systems of Plato in connection with other systems of antiquity. In Proceedings of the Kiev Theological Academy 2: 29-54.

3. Aristotle (1983) Collected works of 4 volumes (V4) Moscow: Enlightenment, Russia.

4. Losev AF (2000) The history of ancient aesthetics: [volumes 1-8]. Moscow: AST; Kharkov: Folio [V1]: Early classics; [V4]: Aristotle and the late classics,Russia.

5. Yue Ji (2008) Confucius On Music Education. In: Nebula 5.1/5.2: 128133.

6. Helmholtz G (2013) The doctrine of auditory sensations as the physiological basis for the theory of music / Translation from German; ed. 3rd. Moscow: KD Librobom, Russia.

7. Stumpf C (1873/1965) Über den psychologischen Ursprung der Raumvorstellung. Leipzig: S. Hirzel; reprint by Bonset: Amsterdam, Netherlands.

8. Stumpf C (1911/1979): Die Anfänge der Musik. Leipzig: Johann Ambrosius Barth; reprint by Olms: Hildesheim, Russia.

9. Sachs C (1953) Rhythm and Tempo: A Study in Music History. New York: Norton, USA.

10. Sachs C (1943/2008) The Rise of Music in the Ancient World: East and West (Dover Books on Music). New York: Dover Publications, USA.

11. Jaques-Dalcroze É (1920/1965) Le rythme: la musique et l'éducation. Paris: Fischbacher; réimprimer par Foetisch Frères éditeurs.

12. Asafiev BV (1971) Musical form as a process. Ed. The 2 nd. Moscow: Music, Leningrad Branch, Russia.

13. Astafyev VP (2008) Zatesi. Moscow: Eksmo, Russia.

14. Garbuzov NA (1955) The zone nature of dynamic hearing. Moscow: Muzgiz, Russia.

15. Garbuzov NA (1956) Zone nature of timbre hearing. Moscow: Muzgiz, Russia.

16. Mazel LA, Tsukkerman VA (1967) Analysis of musical works. Moscow: Music, Russia.

17. Medushevsky VV Music therapy: a view from the depth of music [Electronic resource].

18. Nazaikinsky EV (1972) On the psychology of musical perception. Moscow: Music, Russia.

19. Teplov BM (1947) Psychology of musical abilities. Moscow-Leningrad: PHN of the RSFUR, Russia.

20. Sohor AN (1975) Sociology and musical culture. Moscow: Soviet composer, Russia.

21. Petrushin VI (2006) Musical psychology: a textbook. Moscow: Academic Project, Russia.

22. Bodalev AA (1970) Formation of the concept of another person. Leningrad: Publishing house of Leningrad State University, Russia.

23. Golovinsky GL (1980) On the variability of perception of the musical image. In: Perception of music. Moscow: Music, Russia.

24. Schoen M (1945/2000) The Understanding of Music. NY: Harper \& Brothers, USA.

25. Zhinkin NI (1958) Mechanisms of speech. Moscow: PHN of the RSFUR, Russia.

26. Heine G (2008) Thoughts and aphorisms. Moscow: Eksmo-Press:70 c, Russia. 
27. Kabalevsky DB (1977) A large reserve in the pedagogical arsenal: [unity ethical. esthete. in the ped. system VA Sukhomlinsky]. In: The Communist 13: 90-92.

28. Scheid P, Eccles JC (1975) Music and speech: Artistic functions of the human brain. In: Psychology of Music 3: 21-35.

29. Zatorre RJ, Belin P, Penhune VB (2002) Structure and function of auditory cortex: music and speech. In: Trends in Cognitive Sciences 6(1): 37-46.

30. Green S (2011) Biological Rhythms, Sleep and Hypnosis. London: Palgrave Macmillan, London.

31. Golubeva EA (1972) Reaction of the imposition of rhythm as a method of investigation in differential psychophysiology. In: Problems of differential psychophysiology 7: 15 .

32. Luria AR (1974) Neuropsychology of memory. (Impaired memory in local brain lesions). Moscow: Pedagogy, Russia.

ISSN: 2574-1241

DOI: $10.26717 / B J S T R .2018 .09 .001752$

Aftimichuk Olga. Biomed J Sci \& Tech Res

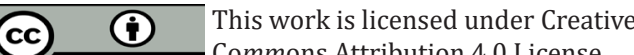

Submission Link: https://biomedres.us/submit-manuscript.php
33. Gray W (1966) The living brain / Trans. with English. Moscow: World, Russia.

34. Ukhtomsky AA (1978) Parameter of physiological lability and nonlinear theory of oscillations. In: Selected Works. Leningrad: Science: 187-194.

35. Razhnikov VG (1989) Dialogues about musical pedagogy. Moscow: Music.

36. Khomyakova VM (2000) The role of music in the education of the moral and aesthetic culture of children: Dis. dr. ped. sciences. Kazan.

37. Kleptsova EYu (2012) Humanization of interpersonal relations in educational activities. Kirov: Ed. Vyatka State University for the Humanities, Russia.

$\begin{array}{ll}\text { BIOMEDICAL } & \text { Assets of Publishing with us } \\ \text { RESEARCHES } & \text { - Global archiving of articles } \\ & \text { - Immediate, unrestricted online access } \\ & \text { - Rigorous Peer Review Process } \\ & \text { - Authors Retain Copyrights }\end{array}$

